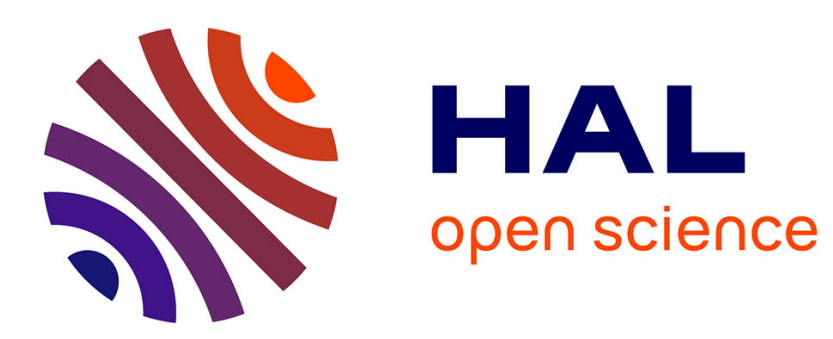

\title{
Design By Additive Manufacturing: an application in aeronautics and defence
}

Frédéric Segonds

\section{To cite this version:}

Frédéric Segonds. Design By Additive Manufacturing: an application in aeronautics and defence. Virtual and Physical Prototyping, 2018, 13 (14), pp.237-245. 10.1080/17452759.2018.1498660 . hal02453852

\section{HAL Id: hal-02453852 \\ https://hal.science/hal-02453852}

Submitted on 24 Mar 2020

HAL is a multi-disciplinary open access archive for the deposit and dissemination of scientific research documents, whether they are published or not. The documents may come from teaching and research institutions in France or abroad, or from public or private research centers.
L'archive ouverte pluridisciplinaire HAL, est destinée au dépôt et à la diffusion de documents scientifiques de niveau recherche, publiés ou non, émanant des établissements d'enseignement et de recherche français ou étrangers, des laboratoires publics ou privés. 


\title{
Design By Additive Manufacturing: an application in aeronautics and defence
}

\author{
Frédéric Segonds \\ LCPI, Arts et Métiers ParisTech, Paris, France
}

\begin{abstract}
Additive Manufacturing (AM) is a major challenge for the deployment of Industry 4.0 in companies. Thus, it becomes essential to control the potential contributions of this innovative process from the early stages of design. In this paper, previous Design and Creativity For/With/Through AM approaches are first reviewed comprehensively and classified into distinct categories according to their main purpose and application. Then, they are integrated into a modular framework as part of a global 5-step design approach to promote AM in the whole design process: the Design By Additive Manufacturing (DBAM) methodology. A validation of the method is then proposed on an industrial case study from the aeronautics and defence sector, thereby fostering the complete exploitation of AM potentials and the development of AM-conformal designs.
\end{abstract}

\section{KEYWORDS}

Additive manufacturing; design methodology; creativity; design by AM

\section{Introduction}

Additive Manufacturing has become of major interest in recent years. This industrial process has many advantages such as the capability to manage part complexity (Gibson et al. 2010). However, when dealing with the early stages of (additive) design, only few methodologies are proposed to enhance design and foster creativity and innovation : continuous support in the entire design process is scarcely available (Laverne et al. 2014). The aim of this paper is to propose and test in an industrial context a design methodology, based on AM process, named Design By Additive Manufacturing (DBAM). The main research question we want to answer is : how can we take profit from the AM design complexity in the whole product life cycle to answer this question, we will first present a review of design and creativity methods oriented for AM processes. We will then especially focus on the Design By AM methodology. Finally we will apply it to an industrial use-case in order to measure its efficiency. We will conclude and propose some future works on the topic.

\section{State of the art}

In this section, we will first present Design For AM (DFAM) and Design With AM (DWAM) methodologies, as a way to foster innovation. These methodologies are named DXAM in the rest of the paper. Especially, DWAM will be useful to propose tailored AM Knowledge for design stakeholders. Then we will focus on Creativity Through AM (CTAM) approach that allows to break cognitive barriers built by traditional processes in design teams, and to enhance breakthrough innovation. Finally, we will present limits of these approaches when dealing with product innovation.

\subsection{Design For $A M$ and Design With $A M$ methodologies}

\subsubsection{Design For $A M$ in the innovation process}

The term DFAM is far from being used consistently among researchers (Kumke et al. 2016). In a highly competitive marketplace, the reduction of time to market, the decrease of production costs and total quality are major concerns meanwhile the number of product requirements is increasing (Pinquié 2016). Design For $X$ (DFX) methodologies which are the 'natural response to improve profitability' (Fitzgerald et al. 2010) combine approaches of interaction and integration and enable the improvement of 'design product as well as design process from a particular perspective which is represented by X' (Tomiyama et al. 2009). DFX also revolutionises the practice of design because all product lifecycle considerations are taken into account through the introduction of comprehensive knowledge, procedures or metrics. Thus, DFAM methodologies are specifically dedicated to the AM paradigm. They are intended to facilitate the consideration of the AM specificities and they provide 'an opportunity to rethink [design for manufacturing] to take advantage of the unique capabilities of these technologies' (Gibson et al. 2010). For Laverne et al. (2015), current DFAM methodologies can be 
classified according to their product systemic level: component or assembly level. Component-based DFAM (CDFAM) methodologies are dedicated to an AM suitable and $A M$ optimised component designed from a given product architecture (or working structure). Firstly, numerical tools are used, such as topological optimisation tools or multiphysics simulation ones, in order to take advantage of AM opportunities and thereby develop components with improved performance. Furthermore, C-DFAM give a great prominence to the integration of manufacturing constraints related to the limits of AM processes (dimensional accuracy, surface finish or porosity). Thus, in C-DFAM, the gap between the theoretical model (CAD model) and the actually achieved component is minimised. Assembly-based DFAM (A-DFAM) are focusing on the product as a whole and are currently far fewer. They are used for the improvement of a product's architecture through a decrease in the number of components, or for the design of new one. For that, A-DFAM considers different functions gathering into functional sets. From these sets, AM compatible working structures are identified using either CAD model in databases or assessment tools (e.g. FMEA or flowforce diagram) combined with a component design stage.

\subsubsection{Design For $A M$ methods lack innovation}

According to Von Stamm (2008), there is no innovation without design stages. Design process is also the backbone of an innovation process and early design stages, starting from the research of concepts to the delivery of a preliminary layout (Segonds et al. 2016), are the key stages in innovative design. Furthermore, creativity plays a major role 'in the production of novel and useful ideas by an individual or a small group of individual working together' (Amabile 1988) during the preliminary design. Indeed, at this time designers are working to develop 'creative outputs' (Howard et al. 2008), i.e. design outputs that satisfy two essential criteria for the development of a radical innovation: originality and appropriateness. Among the various typologies of innovation, the C-DFAM and A-DFAM methods are considered according to their product innovation potential. In these methodologies, the integration of AM Knowledge is not used for challenging the specifications obtained during the preliminary studies or for defining new ideas or concepts. Thus their deliverables are mostly redesigned products; leading to an incremental innovation at the assembly level. In C-DFAM, working structures are not considered. Their components are really different (e.g. new shape or new materials) so that they improve the product performances. However, as Henderson and Clark (1990) explain, the sum of component innovation does not lead to a radical innovation for the product as long as the architectural knowledge is not questioned (i.e. the 'linkages between components and the working structure'). In A-DFAM, the working principle remains unchanged and the working structure evolves in order to fit with the new requirements and constraints such as costs decrease or manufacturing and assembly cycle shortening. It is also a redesigned solution because only some links are challenged. Moreover, DFAM methodologies are not adequate to produce creative outputs because there is no attempt to find new ideas or concept but rather to adapt or transform them according to the AM possibilities.

However an architecture is deemed innovative if the concept itself is considered creative and if the arrangement of the different components ensures compliance with the specifications and the technical constraints of the $\mathrm{AM}$ and/ or traditional processes. It is therefore essential to develop a methodology that helps designers to break free of their architectural knowledge and to think about new concepts that could become creative product architectures.

\subsection{Design With $A M$ as a means to foster innovation}

DWAM methodology was developed by Laverne et al. (2016) in order to take into account the AM Knowledge (AMK) inputs in the early design stages. Thus, this is intended to fill the gap mentioned above through an intake of AMK, suitable to the early design process. Since AM opportunities and restrictions are poorly mastered by designers compared with those about traditional processes, there is strong interest in a Design With X (DWX) methodology enriched with AM paradigm, called Design With AM (DWAM) (Figure 1). DWAM use $A M$ as an extra track to increase the creative potential of designers. But it also involves the introduction of a suitable AMK in order to enable the undermining of the architectural knowledge. Then, when creative concepts are available, the use of DFAM methodologies is possible to optimise performances and arrangements of the components.

The DWAM model defines five specific contributions of AMK during the early design. Three of them improve the ideation stages and the two others are dedicated to the selection stages. Innovative AM process can also help design team to be more creative in the early design stages. In the next section, we will focus on Creativity Through AM (CTAM) approach that allows to break cognitive barriers built by traditional 


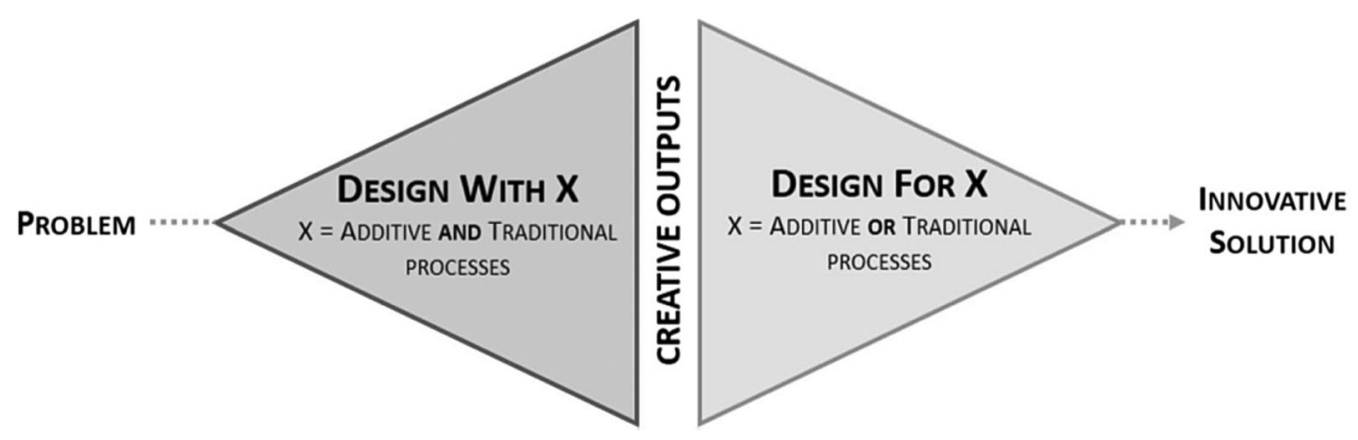

Figure 1. DWX and DFX methodologies (Laverne et al. 2016).

processes in design teams, and to enhance breakthrough innovation.

\subsection{Creativity Through Additive Manufacturing model}

Rias et al. (2016) developed a 5-phase model of Creativity Through AM (Figure 2(A)). This model is intended to guide the designers activities, who usually use little of their creative capacity, and to actors from non-expert industrial firms in design, AM or creativity. This CTAM method is rooted in Bin Maidin et al. (2012)'s approach but with the integration of other domains examples inspiration. The forced and systematic association of two different domains examples is inspired by the work of Yoon and Park (2005) on morphology analysis to forecast R\&D opportunities. The method can be used by both engineers and industrial designers who already have knowledge about AM processes. It is intended to impulse R\&D collaborations between designers and industrial stakeholders interested in emphasising the use of AM in their sectors. This framework is dedicated to AM design projects only, not to projects where the choice between AM or conventional processes is not yet done (see previous DWAM method for that). The method starts when general design specifications are available. The framework of this CTAM method is represented and illustrated with an example in Figure $2(A, B)$ with the generation of a creative AM concept of a turbine blade, in the field of aeronautics and defence.

(1) Features Discovery (Figure 2(A), stage 1): the first task for R\&D designers is to gather examples of AM products (i.e. features already realised in $A M$ ) and other domains examples (i.e. features not yet realised in AM). The examples can be represented by pictures, words or artifacts. The purpose of this stage is to have a great view of what has been done and what can still be created. The survey has to be regularly enriched to update the two taxonomies. Then, designers name the examples' features with keywords and 3D model these features in a simplified and editable manner. In the showed illustration (Figure 2(B), stage 1) a turbine blade is identified among others as a product already realised in AM. It is described by two keywords : rotative and internal channel. Two others domains examples 'color ink' and 'a steel ball' have been identified, among others, as not yet linked to AM. Their typical features are named leave a trace and roll. As an output, designers form an extended portfolio of examples.

(2) Exploration (Figure 2(A), stage 2): this stage consists in randomly and systematically associating an example of one wheel (see the 'two-wheels schema', internal and external) to an example of the other wheel. At least one idea should be formulated for each association. For example (Figure 2(B), stage 2), blade's features are associated to 'color ink' and 'steel ball' features to generate the idea of 'a blade that integrates a color ink in its internal channel' and 'a steel ball at the end of it in order to leave a trace when it's rolling'. Similar to a cartridge the idea is called 'the cartridge blade'. The idea is represented by modifying the input 3D model. The output of this stage is a case-base of various and numerous ideas that present potential opportunities for R\&D.

(3) Ideas evaluation (Figure 2(A), stage 3): a first idea evaluation is conducted by AM experts. The generated ideas are faced to AM processes in order to scale the ideas at a mature level. Some associations could be evaluated as impossible due to major technical limit or risk. The association would then be eliminated. The proof of the ideas feasibility is established by additively manufacturing them as shown in Figure 2(B) stage 3. This stage leads to a reduced portfolio of ideas embodied in artifacts.

(4) Concept generation (Figure 2(A), stage 4): the artifacts and their manipulation stimulates analogical reasoning to translate the previous ideas into concepts which show application scenarios. As shown in our 


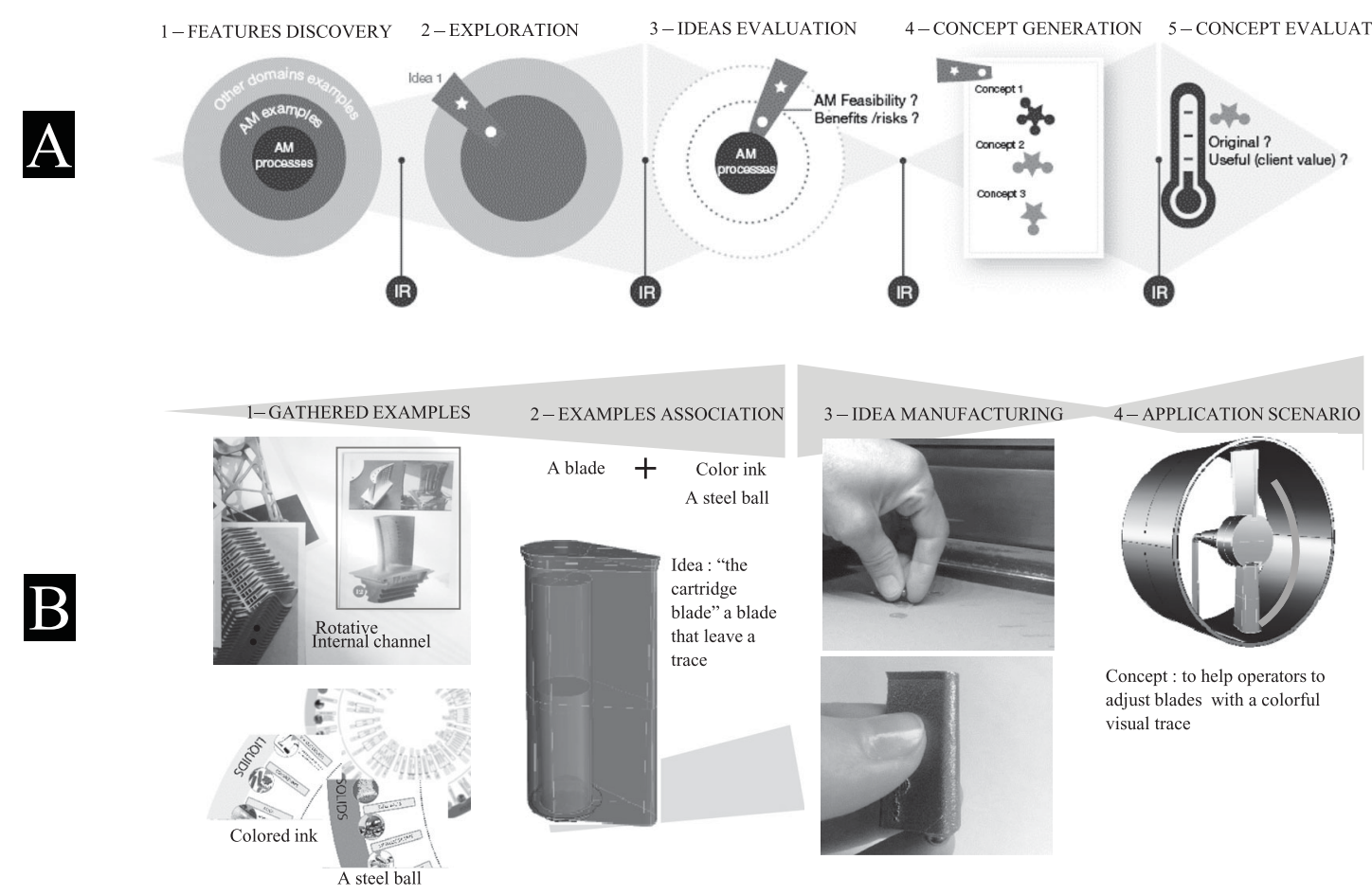

Figure 2. Framework of the CTAM method and example of a generation of a creative AM concept adapted from Rias et al. (2016).

example (Figure 2(B), stage 4), the scenario of a 'cartridge blade' used to help operators in adjusting rotative blades has been formulated. The blades should leave a constant and uniform trace on the support if they are well adjusted. This stage is conducted by designers in a co-design approach with industrial stakeholders in order to enhance the formulation of concepts with a high client value. This stage output is a base of concepts sheets describing potential products to be developed for industrial sectors.

(5) Concept evaluation (Figure 2(A), stage 5): the purpose is to identify the concepts to be further detailed and optimised in downstream DFAM stages. The required profiles for the evaluation are experts of AM who have a good understanding of industrial sectors where AM is integrated, such as innovation managers, senior designers and trade engineers for example. They are asked to quantify the generated concepts on their: 1/ Originality (in the sense of new) regarding traditional products of the involved industrial sector and regarding $A M$ industry, 2/ Usefulness regarding the involved industrial sector (client value), 3/ Realism regarding AM capacities. For example, the 'cartridge blade' is considered new since it integrates new functions and forms, and since the associated features have not been already realised in AM industry.

\subsection{Limits of Creativity Through $A M$ and Design For \& With AM methodologies}

Literature review and the analysis of DXAM and CTAM in the context of innovative product design expose three overarching limitations of existing approaches which provide, at the same time, promising research opportunities:

(1) Missing integration into a common framework: although DXAM is understood as a concept covering all design phases from product requirement/idea to design solution, no continuous and efficient framework in the style of Pahl \& Beitz (Pahl et al. 2007) is available for AM products.

(2) Partitioning of DXAM approaches: previous research is fragmented. Almost all DXAM and CTAM approaches are developed independently and do not logically follow one another. For example, the AM Knowledge provided in the DWAM approach is not used in the specification phase of the product.

(3) Less attention to the creative phases: very few methodologies are available to inspire creative designs in the conceptual phase (Doubrovski et al. 2011, Bin Maidin et al. 2012). Therefore, a systematic utilisation of AM potentials is limited by cognitive barriers as a result of conventional process capabilities that have 
to be broken to exploit the full potential of AM. For this reason, specific geometries induced by manufacturability limitations should not be taken into account too early in AM product development processes.

To fill these methodological gaps, an integrated modular framework to promote $\mathrm{AM}$ in the whole product lifecycle has been developed: the Design By AM approach.

\section{Design By AM methodology}

DBAM is a global framework that fosters innovation by taking into account AM process from the early design stages (Figure 3). It is a 5-step model, 24-sub-step, with forth and back loops between it. We hereunder describe the aim of each step. This model is intended to be used in a collaborative team, with various fields of expertise in order to enhance AM-oriented designs.

(1) First of all, the aim of the 'Knowledge Synthesis' phase is to capitalise and then exploit the necessary knowledge related to the product and/or the AM process. In this step, we particularly noted the relevance of taking into account the knowledge related to the AM process, but also some more 'downstream' phases such as the constraints related to the design induced by step 4 'Design and Evaluation', or those coming from the 'Control' step of the component. In this 'Knowledge Synthesis' step, we recommend following the DWAM method of upstream integration of knowledge related to a technological innovation.

(2) Next, the 'Product Specification' phase aims to precisely characterise the product to be designed through its requirements. The influence of an optimisation of this step to help designers to identify the inconsistencies between the specifications is high. In this 'Product Specification' step, we recommend to use the digital environment design method dedicated to the search and collaborative synthesis of product engineering requirements, proposed by Pinquié (2016).

(3) The 'Concept Generation' phase, makes sure to fully exploit the unique features of AM processes when generating innovative concepts. More specifically, the CTAM approach combined to the AM of Intermediate Objects (Rias et al. 2017) and creative stimuli is able to stimulate the creativity of designers. In this step, we recommend to follow the CTAM approach.

(4) The 'Design and Evaluation' phase then aims to ensure that the concept generated is 'AM feasible'. This step makes particular use of topology optimisation methods (Fey et al. 2009) and requires validation of the pre-industrialisation of the component on at least one prototype part. In this 'Design \& Evaluation' step, we recommend a C or A-DFAM approach, depending on the initial requirements (Laverne et al. 2015).

(5) Finally, the purpose of the 'Control' phase, in an industrial process, is to ensure that the produced part complies with the requirements, in particular dimensional ones, defined during the 'Product Specification' phase. In this 'Control' step, we recommend following the method of Manufacturing Execution System integrated into DFAM proposed by D'Antonio et al. (2017).

In order to implement this method, we present in the following section an industrial case study of the deployment of DBAM on a complex optronic part.

\section{Case study}

In order to validate the proposed method, an industrial case study is presented in this section. The DBAM methodology presented above has already been tested on academic use-case (Segonds 2018). An application in the aeronautics and defence sector was chosen in order to reinforce the CTAM example, presented in Figure 2. The objective here is to test the DBAM method in a complex industrial context and to propose an optimised design path that promotes product innovation in a constrained environment. For this, an initial machined product composed of 5-components and 16 functions has been studied. Concepts generated were prototyped before the additive metal manufacturing of these by the SLM process. It results in a 1-component product fulfilling 20 functions. The global application of DBAM method on this use-case is synthetised on Figure 4. The users of DBAM were part of a company's team composed by 3 persons: a novice user with a mechanical engineering background, a 3-year experienced engineer with knowledge of optronics parts, a 10-year expert in $\mathrm{AM}$ engineer.

\subsection{Context}

In this chapter, we are interested in a guide piece whose design needs to be modified in order to take advantage of AM processes. This product, called '4 Mirrors Head' serves to guide autonomous flying devices (see Figure 4, left). Thus, via this study, we have proposed an integration of the DBAM in an industrial context. The objective of this product is to orient a line of sight. A mirror is rotatable about the misalignment axis, and the light rays are then 


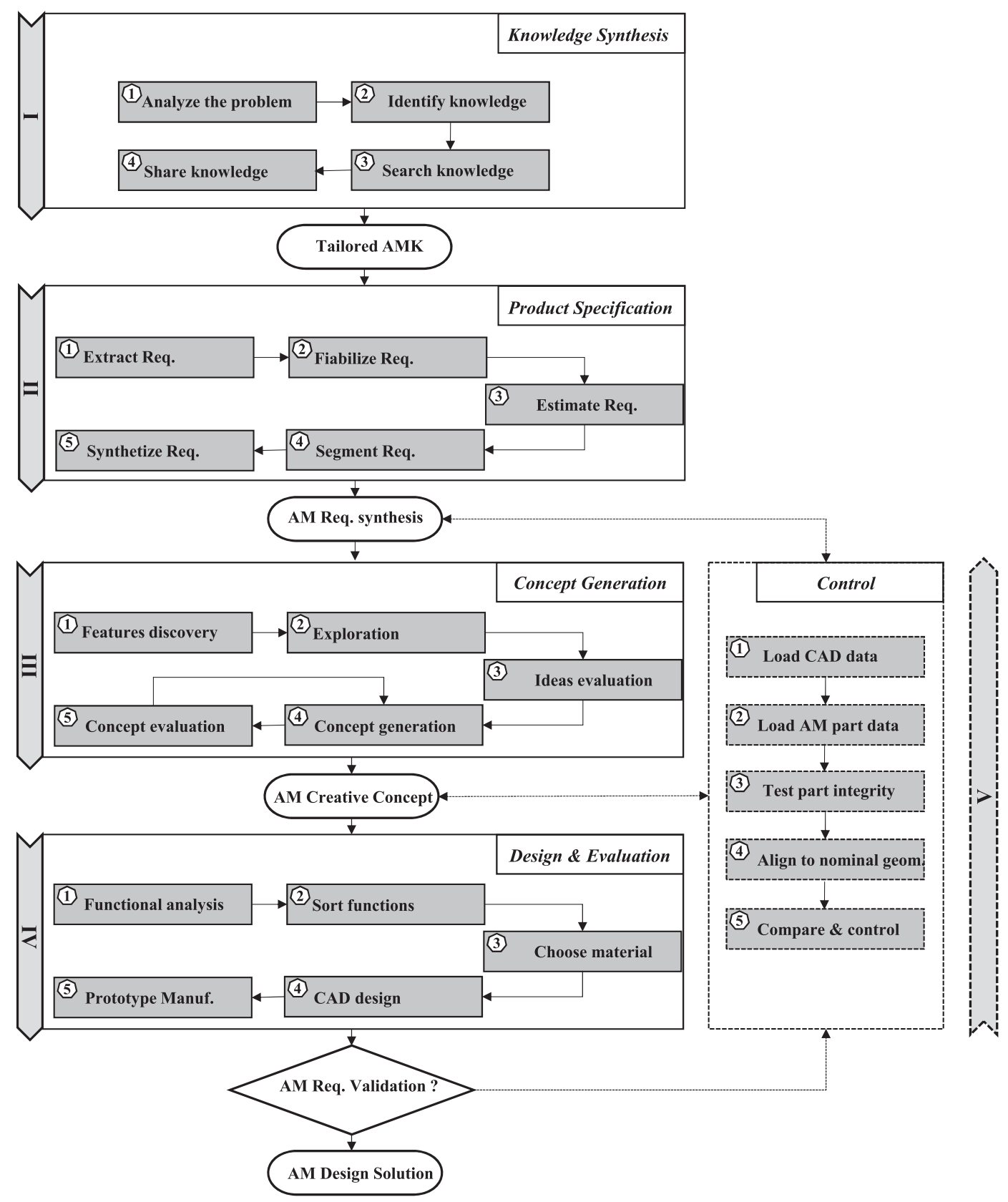

Figure 3. Global framework for Design By Additive Manufacturing methodology.

reflected by 3 mirrors to the optical equipment. The dimension of this head is about $100 \mathrm{~mm}$ for each side. It must respect many constraints especially mass and stiffness. An AM solution has been studied to determine if this innovative process can optimise design parameters. The central objective of this case-study is to fully redesign the product for AM. In the next chapter, we present the results obtained by using DBAM methodology.

\subsection{Results}

The synthetic scheme of the overall method, as well as the main contributions, is presented in Figure 4. The approach is illustrated by its application on the product. However, the details provided below describe the approach in a general context.

After identifying the needed knowledge in this usecase (AM part manufacturing in optronics applications), the user uploads it on a DWAM software tool (Laverne 2016) in order to share it to all the design stakeholders. This knowledge represents business rules that must be traced and made available to designers from the company.

Then the specification of the product is made in a collaborative way. Requirements are extracted from existing documents, fiabilised and collaboratively 


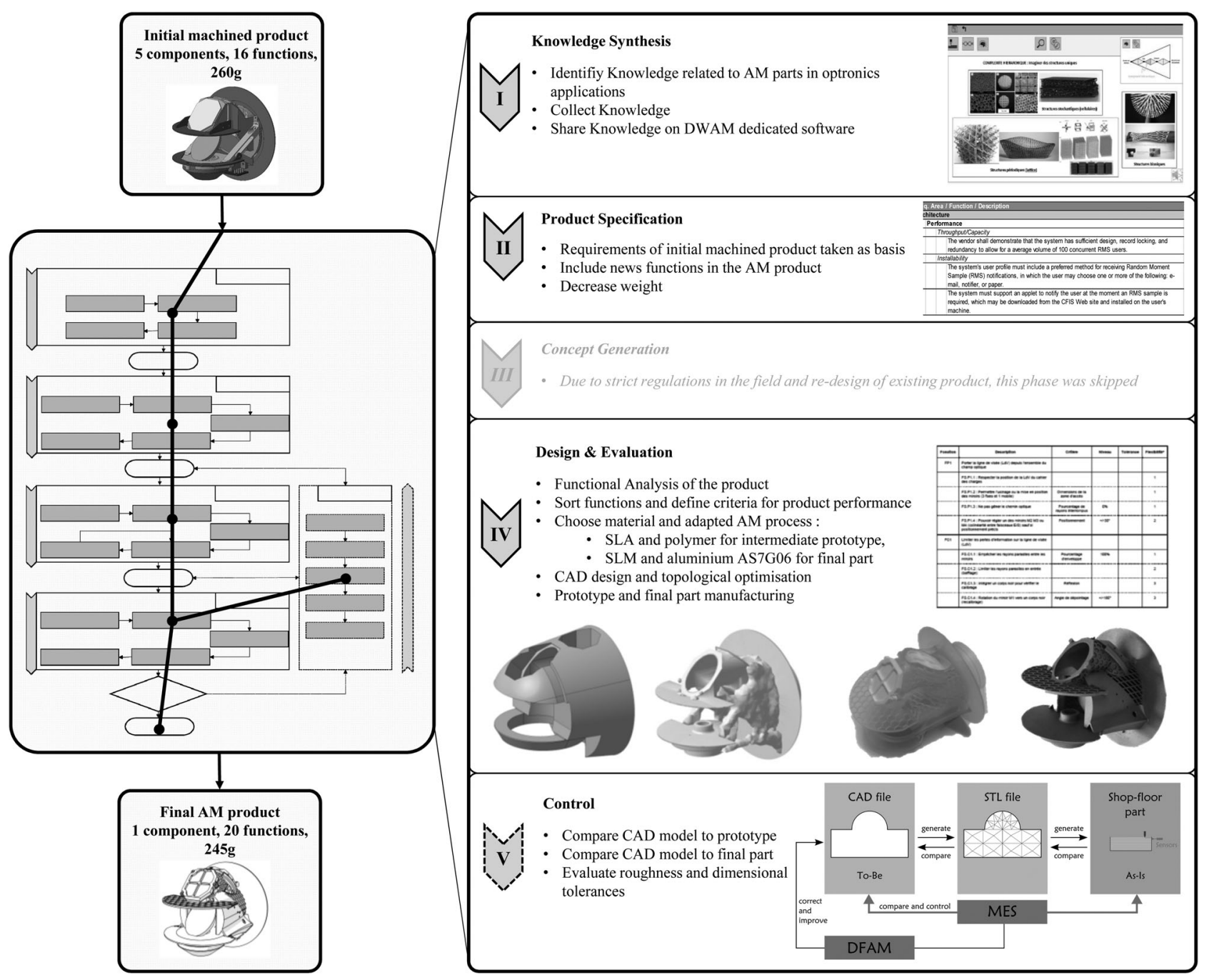

Figure 4. DBAM application to a complex optronic part.

synthetised in a product engineering requirements table. It results in a requirements list inspired from the initial product one but with specificities such as the increasing number of functionalities and the weight optimisation.

Then, the user enters the 'Concept Generation' phase. In this use-case, this step was useless as the place for creativity and breakthrough innovation was minimal. To illustrate this stage, the reader can refer to chapter 2.3, from the same sector but on a different case study.

The user is then oriented to the 'Design and Evaluation' phase. A-DFAM methods are used as design is focused on the product as a whole (5 components, 16 functions). The aim here is to provide a functional analysis of the product in order to identify the most important functions and the associated evaluation criteria. For example, we can cite the function 'Do not interfere with the optical path' and the associated criteria:
'Percentage of interrupted light ray'. Then, the design stakeholders have to choose the appropriate AM process and materials. They identify SLA and SLM as the most suitable technologies supported by an AM process selection system. In this use case, a first prototype has been made in polymer through an SLA process. Ergonomics and mountability test of accessories were conducted on it. After that, a second prototype was manufactured in aluminium through an SLM process. Once process and materials are selected, the CAD design allows, thanks to topological optimisation and dynamic simulations to define the best geometry for both prototypes. The user is provided with specific AM oriented design rules and CAD functions to create an AM-conformal design.

The user is then directed to module 5 'Control' where he gains information on roughness and dimensional tolerances compared to the CAD nominal geometry. 
Process parameters (laser speed and part orientation) have been modified in order to respect the specifications. In addition to weight reduction (5\%) achieved, component count is reduced from 5 to 1 which leads to lower assembly costs and higher reliability.

The case study demonstrated that designers can produce AM-optimised products if they are (1) working in a collaborative way from the first stages of design with experts from different fields, (2) provided with customised guidance through the design process and if selected existing tools and knowledge are given in a just in time and just need approach (Laverne 2016). The many possible combinations of this unique framework and its internal phases are covering the whole product design lifecycle. In contrast, previously published DXAM methods are usually not tested in a complex industrial environment. They also often have a lower degree of detail, and do not integrate other AMspecific design tools and methods.

\section{Conclusion and future work}

In this paper, previous research on DXAM and CTAM is reviewed and their limits are commented. A global Design By AM framework is proposed and tested on an industrial use-case. The main research question of this paper is: how can we take profit from the AM design complexity in the whole product lifecycle? In order to fully use the potential of AM paradigm, we propose to exploit DBAM methodology from the early design stages in a collaborative way. As perspectives, we are aware that some other steps are necessary before the final part can be used in an industrial way, e.g. elimination of supports, T6 heat treatment, machining recovery, painting or end of life. Future works will consist in integrating this phases in the global framework to provide a full methodology from (additive) idea generation to the end of life of the product.

\section{Disclosure statement}

No potential conflict of interest was reported by the author.

\section{Notes on contributor}

Frédéric Segonds is Associate Professor of Mechanical Engineering at Arts et Metiers ParisTech School of Engineering in Paris, France and member of the Product Design and Innovation Laboratory (LCPI). His research interests focus on Product Lifecycle Management (PLM), early stages of design collaboration optimization and Creativity and Design With/For Additive Manufacturing (DWAM/DFAM).

\section{References}

Amabile, T.M., 1988. A model of creativity and innovation in organizations. Research in Organizational Behavior, 10 (1), 123-167.

Bin Maidin, S., Campbell, I., and Pei, E., 2012. Development of a design feature database to support design for additive manufacturing. Assembly Automation, 32 (3), 235-244.

D'Antonio, G., et al., 2017. A framework for manufacturing execution system deployment in an advanced additive manufacturing process. International Journal of Product Lifecycle Management, 10 (1), 1-19.

Doubrovski, Z., Verlinden, J.C., and Geraedts, J.M.P., 2011. Optimal design for additive manufacturing: opportunities and challenges. In: ASME 2011 international design engineering technical conferences and computers and information in engineering conference. Washington, DC: ASME, 635-646.

Fey, N.P., et al., 2009. Topology optimization and freeform fabrication framework for developing prosthetic feet. In: Solid freeform fabrication symposium. Austin, TX: Library of Congress, 607-619.

Fitzgerald, D.P., Herrmann, J.W., and Schmidt, L.C., 2010. A conceptual design tool for resolving conflicts between product functionality and environmental impact. Journal of Mechanical Design, 132 (9), 091006.

Gibson, I., Rosen, D.W., and Stucker, B., 2010. Design for additive manufacturing. additive manufacturing technologies: rapid prototyping to direct digital manufacturing. Boston, MA: Springer, 299-332.

Henderson, R.M. and Clark, K.B., 1990. Architectural innovation: The reconfiguration of existing product technologies and the failure of established firms. Administrative Science Quarterly, 35, 9-30.

Howard, T.J., Culley, S.J., and Dekoninck, E., 2008. Describing the creative design process by the integration of engineering design and cognitive psychology literature. Design Studies, 29 (2), 160-180.

Kumke, M., Watschke, H., and Vietor, T., 2016. A new methodological framework for design for additive manufacturing. Virtual and Physical Prototyping, 11 (1), 3-19.

Laverne, F., 2016. Concevoir avec la fabrication additive: Une proposition d'intégration amont de connaissances relatives à une innovation technologique. (PhD). Arts et Metiers ParisTech.

Laverne, F., et al., 2014. DFAM in the design process : a proposal of classification to foster early design stages. CONFERE'14. Sibenik, Croatia, 12.

Laverne, F., et al., 2015. Assembly based methods to support product innovation in design for additive manufacturing: An exploratory case study. Journal of Mechanical Design, 137 (12), 121701

Laverne, F., et al., 2016. Enriching design with X through tailored additive manufacturing knowledge: a methodological proposal. International Journal on Interactive Design and Manufacturing (IJIDeM, 11 (2), 279-288.

Pahl, G., et al., 2007. Engineering design - A systematic approach. Londres: Springer.

Pinquié, R., 2016. Proposition d'un environnement numérique dédié à la fouille et à la synthèse collaborative d'exigences en ingénierie de produits. $(P h D)$. Arts et Metiers ParisTech.

Rias, A.L., et al., 2016. Design for additive manufacturing: a creative approach. In: DESIGN 2016 14th international design conference, May 2016. Dubrovnik, Croatia, 411-420. 
Rias, A.L., et al., 2017. Towards additive manufacturing of intermediate objects (AMIO) for concepts generation. International Journal on Interactive Design and Manufacturing (IJIDeM), 11 (2), 301-315. doi:10.1007/s12008-017-0369-0

Segonds, F., 2018. Une approche méthodologique de numérisation au juste besoin du processus de conception et d'innovation par la fabrication additive: le Design By Additive Manufacturing. (HDR). Université Grenoble Alpes.

Segonds, F., et al., 2016. PLM and early stages collaboration in interactive design, a case study in the glass industry. International Journal on Interactive Design and
Manufacturing (IJIDeM), 10 (2), 95-104. doi:10.1007/s12008014-0217-4.

Tomiyama, T., et al., 2009. Design methodologies : industrial and educational applications. CIRP Annals - Manufacturing Technology, 2009.09.003 (in press).

Von Stamm, B., 2008. Managing innovation, design and creativity. Hoboken, NJ: Wiley.

Yoon, B. and Park, Y., 2005. A systematic approach for identifying technology opportunities: keyword-based morphology analysis. Technological Forecasting and Social Change, 72 (2), 145-160. 